This is a postprint of Huvila, I. \& Ahmad, F. Holistic information behavior and the perceived success of work in organizations. Library \& Information Science Research, 2018, 40(1), 18-29 DOI: 10.1016/j.lisr.2018.03.004

\title{
Holistic information behavior and the perceived success of work in organizations
}

Isto Huvila ${ }^{1}$, Farhan Ahmad ${ }^{2}$

Uppsala University, Engelska parken, Thunbergsv. 3H, 75126 Uppsala, Sweden

Faculty of Social Sciences, Business and Economics, Åbo Akademi University, Tuomiokirkontori 3, FI-20500 Turku

\begin{abstract}
Surprisingly little is known about the relationship between perceived work success and information behavior. This study shows that holistic (versus organization-centric) information behavioral preferences are related to interaction and exchange oriented perceptions of the success of work. The findings were drawn from a partial least square structural equation modeling (PLSSEM) based analysis of the survey data $(N=305)$ collected from employees of a large multinational corporation. The findings suggest that holistic information behavior is more strongly related to social measures of success, whereas their association with quantitative measures tends to be lower. From the perspective of information behavior research, the findings suggest that holism seems to be a similar factor to, for instance, task complexity or personality, which influences human information behavior and, for instance, perceptions of relevance. From a practical perspective, the study suggests that the promotion of specific facets of measuring success and patterns of information behavior can be used to influence the orientation of working between centrifugality and openness.
\end{abstract}

\section{Introduction}

Employee perceptions of the success of their work are vital for employers to know because of the linkage between employee success and organizational performance $(\mathrm{Ng}$, Eby, Sorensen, \& Feldman, 2005). In contrast, if they are not realistic, individuals' beliefs regarding their own situation and success can also be counter-productive from the perspective of organization and its members (Martinko, Gundlach, \& Douglas, 2002). A particular aspect of how well the personal and organizational situations converge is the extent to which employees consider their actions related to workplace alone or to their life in a broader sense. Questions about the convergence and boundaries between work and private life have become increasingly crucial in the increasing "intimacy" of work (Gregg, 2011), and the blurring of the boundaries between work and nonwork. This blurring of the boundaries has an impact on how workers perceive and define the

\footnotetext{
${ }^{1}$ isto.huvila@abm.uu.se

${ }^{2}$ farhan.ahmad@abo.fi
} 
success of their undertakings and also has implications for information behavior (IB) when professional and non-professional information practices converge together with work and nonwork, presumably, forming new constellations of professional, non-professional and holistic, combining both information behavioral preferences.

\section{Problem statement}

Even if earlier information science research has unfolded the complex relations of professional and non-professional information spheres (Case \& Given, 2016), there is relatively little research on the perceptions of success and IB (Huvila, 2010), especially in relation to the convergence (and lack of it) of work-specific and lifeworld-wide behaviors. From a workplace perspective, this is striking, considering the critical importance of an effective exploitation of information and knowledge for organizational performance (Huotari \& Wilson, 2001) and the link between individual informational behaviors, values and norms, and organizational performance (Abrahamson \& Goodman-Delahunty, 2013; Bergeron et al., 2007; Choo, 1996; Ginman, 1988). From an individual perspective, the question is equally central considering the linkage of IB and well-being (Heinström, Huvila, Widén, \& Ahmad, 2014; Widén-Wulff et al., 2008). The problem is that without a proper understanding of how success perceptions that inevitably guide IBs and information behavioral preferences are interrelated, a major driver of how and why people interact with information is being disregarded. In a situation where the configurations of work and non-work are changing, a better understanding of the links between holistic and professionally oriented information-behavioral preferences and success perceptions help to make sense of making (and not making) a difference between workplace information and nonworkplace information, and consequently, of the informational dimension of the tension between the lifeworlds of individual employees and their organizations, and its consequences in a workplace.

\section{Literature review}

\subsection{Perceived success}

There is a relative abundance of earlier research relating to work success, especially in relation to personal and career success, motivation, and factors that employees and entrepreneurs link to their successes and failures (Benzing, Chu, \& Kara, 2009; Erickson, Martinengo, \& Hill, 2010). Much of the research has focused on the level of perceived success. Gender differences in perceived success is a classic question in this line of research (Dann, 1995; Orser \& Dyke, 2005). Judge and colleagues have argued that integrative approaches would perform better than individual traits-based approaches (Judge, 2009; Judge \& Hurst, 2008). In contrast to the investigations of career success (and failure), there is considerably less literature that focuses on the characteristics of career success as an issue that would take both self-experienced and social aspects into account (Dann, 1995; Heslin, 2005). Similar tendencies can be observed in the literature on work success in general. It has been common to contrast subjective and objective (Heslin, 2003), internal and external (Gerber, 2002; Porac, Nottenburg, \& Eggert, 1981), and 
economic and non-economic dimensions of success and use them as a starting point for studying the issue (Cooper \& Artz, 1995). The problem with commonly used (to an extent) objective measures (e.g., salary and promotions) is that they are influenced by multiple factors and may not necessarily correlate with the level of success experienced by an individual. Subjective measures tend to be similarly biased. They are dependent on individual assumptions of the organization of work. Further, people tend to compare their achievements to their personal goals instead of juxtaposing their performance with the achievements of others (Heslin, 2003). In spite of their evident shortcomings, salary and promotions are typically the most commonly used measures of success (Heslin, 2003). The variation in the popularity of subjective measures is greater. Multiple studies have used the Greenhaus, Parasuraman, and Wormley (1990) Career Satisfaction Scale (Boudreau, Boswell, \& Judge, 2001; Heslin, 2003; Judge, Heller, \& Mount, 2002). Others, including Peluchette and Jeanquart (2000) and Walker and Brown (2004) have developed alternative instruments with slightly different emphases. In contrast to trait-based measures, Judge (2009) has argued for an approach based on core self-evaluations (self-esteem, locus of control, generalized self-efficacy, and [low] neuroticism, i.e., high emotional stability). His findings show that people with higher core self-evaluations are more successful in their careers and more satisfied in their jobs.

The research carried out in small- and medium-sized enterprises has special relevance from the perspective of a general notion of work success, because in smaller organizations, organizational goals can be assumed to be more closely aligned with the personal preferences of the entrepreneurs (Walker \& Brown, 2004). From a business performance point of view, Hudson, Smart and Bourne (2001) identified performance-to-quality ratio, time, flexibility, finance, customer satisfaction and human resources as critical dimensions of work success. In another study, Orser and Dyke (2005) investigated Canadian business owners and corporate managers' perceived success based on a definition reminiscent of that of Walker and Brown (2004) and Hudson, Smart and Bourne (2001) in its breadth. The survey on corporate managers was based on success criteria incorporating the factors of working with competent people, financial security, employment flexibility, supportive workplace culture, and opportunities to participate in community activities. The second survey, conducted with small business owners, incorporated questions on company profitability, product and service quality, operating performance, and market acceptance.

The most common factors that have been related to different perceptions of success are personality, gender, education, mentoring relationships, and career tactics (Heslin, 2003), even if not all of these factors, like personality, necessarily have an enduring impact on work satisfaction or quantitative indicators of work success such as income (Sutin, Costa, Miech, \& Eaton, 2009). Furnham, Trickey, and Hyde (2012) found that personality disorders are related to work success and failure. In a qualitative investigation of male and female managers, Sturges (1999) identified seven internal (accomplishment, achievement, enjoyment, integrity, balance, personal recognition and influence) and two external (grade and reward) success criteria. Parker and Chusmir (1992) 
studied six different success measures and their importance for female and male managers. In the findings, personal fulfillment and security seemed to be more important to females than males. Among non-managers, women put more emphasis on family relations and personal fulfillment, whereas males were more inclined to appreciate status and wealth. According to the findings of Fenwick and Hutton (2000) women's success perceptions were broader than business success (i.e, profit, size and growth). The participants in their study referred to issues such as personal sense of satisfaction, children, and reputation, and commented explicitly on the secondary importance of economic rewards. The findings of Justo, De Castro, Coduras, and Cruz (2006) were similar to those of Fenwick and Hutton (2000).

\subsection{Information behavior and success}

Earlier information studies research has unfolded the complexity and situatedness of human IB and information practices. As a factor influencing the totality of human pursuits, it has been relatively recently picked up by several neighboring disciplines even if the proposed approaches sometimes lack a certain sophistication (Browne, Cheung, Heinzl, \& Riedl, 2017; Case \& Given, 2016). Both individual and contextual factors influence how information is sought, shared, managed and used (Case \& Given, 2016) and as Krampen (2011) suggests, it is rather apparent that there is no one and only professional, or any other, information-seeking behavior.

Demographic factors, such as age and gender, technology experience, domain knowledge, and cognitive abilities and styles have been found to affect IB (O’Brien, Dickinson, \& Askin, 2017). Other researchers have shown that different cognitive styles have influence on information searching (Bak \& Meyer, 2011; Bowen, Ferguson, Lehmann, \& Rohde, 2003; Goodale et al., 2014). The preference between two major patterns of interacting with information, broader (including browsing and scanning, passive monitoring and incidental acquisition, Bates, 2002) and focused modes of information seeking have been suggested to depend on many factors. Heinström (2006a) found that with graduate students, personal traits were a more powerful predictor of their approach than study discipline. Orientation towards breadth or specificity can also be influenced by, for instance, time (Wilkinson, Reader, \& Payne, 2012), the task at hand and its complexity (Byström, 2000), as well as the situation and other contextual factors. Byström (1999) found that an increased task complexity pushed people to use people as information sources, but was not related to the use of external information. Focused information seeking manifests often in targeted searching, whereas broad IB may include preference for browsing and serendipitous discoveries.

Heinström (2005) identified three information-seeking styles: fast surfing (speed), broad scanning (wide and thorough information seeking) and deep diving (high effort and focus on quality). Further, their information seeking approaches could be divided into three categories: deep, surface, and strategic. A combination of deep and strategic approaches was likely to be related to deep diving, whereas surface strategy tended to relate to fast surfing (Heinström, 2006b). Traces of similar orientations have been found also in other studies (Foster \& Urquhart, 2012). Fast surfing was related to neuroticism, cautiousness (a low level of openness to experience) and 
carelessness (low conscientiousness), broad scanning to an extroverted and competitive (low agreeableness) personality with high openness to experience, and deep diving to high openness to experience (Heinström, 2005). Information flaneur, a concept introduced by Dörk, Carpendale, and Williamson (2011) to describe an information seeker that combines exploration and immersion, and is capable of exploiting the interrelatedness of information activities in a lifeworld, appears to be situated somewhere between broad scanners and deep divers. As a whole, it has been suggested that broader forms of IBs, such as browsing and information foraging, are closer to natural general human behavior (Bates, 2002; O'Connor, Copeland, \& Kearns, 2003; Pirolli \& Card, 1999) than targeted searching.

In addition to the complexity of information activities, another tenet of information research (which is not, however, always well reflected in study designs) is that information practices and information work never take place in isolation and they are seldom the only or principal pursuits of their perpetrators (Huvila, Lloyd, Budd, Palmer, \& Toms, 2016). Even focused information activities are situated in lifeworld-wide "information worlds" (Jaeger \& Burnett, 2010) or as Blandford and Attfield (2010) argue, are a part of an information journey within which information can support specific or broader activities. Similarly, even if it has been common to conduct research either on professional or everyday life (i.e., non-professional) information seeking (ELIS) and behavior (keeping to the "myth of separate worlds" of work and non-work, Kanter, 1977), it is apparent that such a distinction is highly artificial as work is a part of the everyday life (Huotari \& Chatman, 2001; Jaeger \& Burnett, 2010; Johnson, 2003) and workrelated IB is often influenced by and intertwined with non-professional informational activities (e.g., Dankasa, 2016; Ferran-Ferrer, Minguillón, \& Pérez-Montoro, 2013; Huvila, 2013b). Huotari and Chatman (2001) have conceptualized organizations as "small worlds" (Chatman, 1991) and emphasized that "individuals must connect with each other and also go outside the organization to other organizations and individuals to create value" (Huotari \& Chatman, 2001, p. 363). The proliferation during recent decades of flexible and mobile working, catalyzed by the emergence of digital technologies and nearly ubiquitous connectivity has intensified the evaporation of the boundaries between work and other aspects of life (Gregg, 2011). In contrast to typical family-oriented work-life, this shift has emphasized the need to highlight organizational perspectives in the work-life balance (Valcour \& Hunter, 2005) that are also rare in the field of information studies. The convergence of work and non-work related to IB does not mean, however, that workplace and non-workplace would not be distinct contexts with their specific repercussions for information activities (Ferran-Ferrer et al., 2013; Widén, Steinerová, \& Voisey, 2014). Instead of making a clear division between individual contexts, it seems plausible to suggest that, from an individuals' perspective, IB(s) reside on a scale from narrow and small world-oriented to broad, holistic lifeworld-wide ones. The present study suggests that this latter type of holistic information behavior cuts across contexts, is based on a broad exploitation of information from different contexts, and aims at general impact in terms of general understanding and self-development in the context of life-world rather than an individual task. 
The rudimentary idea of the difference between broad and narrow context-specific information seeking can be found in several earlier models of IB. Many of the classical and newer models focus either on task- and context-specific (Bronstein, 2007; Ellis, 1993; Kuhlthau, 1993; Meho \& Tibbo, 2003; Rhee, 2012; Robson \& Robinson, 2013; Wilson, 1997) or broader (Dervin, 1998; Pirolli \& Card, 1999; Savolainen, 1995; Spink, 2010) types of IB, and in a narrower sense, in several of the seeking oriented models (including those of Belkin, Oddy, \& Brooks, 1982; Foster, 2004; and Kuhlthau, 1993), the information seeking workflows incorporate broader orientation and focused consolidation phases. Liu (2017) links together these two broad approaches of taskbased short-term (for solving the task-in-hand) and sense-making oriented long-term (for augmenting one's knowledge base) information seeking and suggests that supply and demand could be used to explain IB in both cases. Work on collaborative information seeking similarly provides clues as to how shifts from acquiring information alone and together with other people can be linked to the problem-in-hand and its complexity (Karunakaran, Reddy, \& Spence, 2013; Reddy \& Jansen, 2008).

However, instead of explaining variation in orientation to IB across contexts, much of the earlier model-building tends to be focused on explaining differences in information seeking for distinct purposes and in relation to specific tasks (whether focused tasks-in-hand or general orientation). Several of the existing models acknowledge the significance of contextuality (Agarwal, 2017), but there is both a lack of consensus on what context is (Beyene \& Byström, 2017) and an inclination to conceptualize context as something highly unique to a given situation and, even at the same time, as a fairly unspecified external setting of a studied information activity, a perspective that has been criticized for some time (Burnett \& Erdelez, 2010; Talja, Keso, \& Pietiläinen, 1999). This applies also to collaborative information seeking research, which otherwise addresses the gap between the individual and social aspects of seeking information. An apparent problem is, as Karunakaran et al. (2013) note, that collaborative information seeking research has had difficulties in defining the scope of collaboration (i.e., the size of the collaborative contexts, such as groups and teams). In addition, from the perspective of holism, collaborative information seeking tends to have a similarly narrow focus on tasks and specific situations than much of the earlier research on individual IB.

Cross-contextuality has been studied in conjunction with personal information management, information sharing, information practices and use, information literacy and boundary-related research (Capra, Khanova, \& Ramdeen, 2013; Huvila, 2013a; Huvila et al. 2017 ; Lloyd, 2006; Meum \& Ellingsen, 2011; Simard \& Rice, 2006), but it has been fairly uncommon to study the information practices of same individuals across different contexts. There are some exceptions and, for instance, studies like the investigation of differences between the use of private and professional email accounts by Capra et al. (2013) provide evidence of how individual preferences and behavioral patterns can carry over contextual boundaries. The expanding corpus of literature on mobile and social media related work and information practices (Allen \& Shoard, 2005; Burford \& Park, 2014; Gregg, 2011; Huvila, 2013a) does also provide glimpses of holistic 
and aholistic tendencies in individuals' informational preferences.

On the level of concepts, it seems that Heinström's (2005) notion of broad scanning comes perhaps closest to the idea of holistic IB even if it is a presented as a style of searching information rather than, as proposed here, a broader information behavioral trait. However, in spite of their differences, it seems plausible that, on a general level, the both are linked to the kind of broad behavioral eclecticism represented also by holistic learning styles (Foster \& Urquhart, 2012) and, for instance, Foster's holism and nomadic thought (2004).

The proposition of the significance of holistic IB is substantiated further by findings from earlier research in information cultures. Earlier research has established that positive information culture supports business performance and success (e.g., Choo, Bergeron, Detlor, \& Heaton, 2008; Ginman, 1988; Widén-Wulff, 2001) and that efficacious informational and social behaviors, values and norms are linked to each other (Widén-Wulff \& Ginman, 2004). Also, the earlier research on social capital proposing that the emphasis of relational social capital (characterized by flexible structures and strategies) leads to centrifugal social opportunities and information practices while structural (firm and solid relations and structures) lead to integrative social opportunities and intensive and introverted information practices (Widén-Wulff et al., 2008) provides additional indications of the relevance of holistic IB. Whereas, in general, higher levels of social capital have been linked to increased information sharing, knowledge acquisition and innovation (Martinez-Canas, Saez-Martinez, \& Ruiz-Palomino, 2012; Mura, Lettieri, Radaelli, \& Spiller, 2013; Widén-Wulff \& Ginman, 2004), there is contradictory evidence on how social engagement in a particular group corresponds with engagement in other groups and in society at large (e.g., Huvila, Holmberg, Ek, \& Widén-Wulff, 2010; Molyneux, Vasudevan, \& Gil de Zúñiga, 2015). It seems that moderate levels of centrifugality and centripedality lead to the best results, or as Di Vincenzo, Hemphälä, Magnusson, \& Mascia (2012) note, intermediate levels of structural holes in social networks (i.e., non-redundancy and heterogeneity of contacts) maximize learning. As Choo (2016) suggests in his congruence hypothesis, it is also probable that the alignment of the mission, strategy, and criteria for success for an organization and its information culture has an impact on its effectiveness. At the extremes, a strong presence of structural forms of social capital can lead to confinement in (using the term of Chatman, 1999) a life in the round and impoverishment of information world (Buchanan \& Tuckerman, 2016). Many different reasons from stigmatization, marginalization, feelings of belonging, trust and lack of it, and experiences of vulnerability may contribute to the dominance of structural, bonding type of social capital (Ahmad \& Widén, 2015; Hall \& Widén-Wulff, 2008; Veinot, 2010; Widén-Wulff et al., 2008).

In summary, earlier research shows that information behavior is a complex phenomenon. Multiple studies provide evidence of the impact and often positive effects of cross-contextual information activities but, as a whole, earlier research and existing models of information behavior do not account specifically for the impact of holistic versus narrow approaches to 
information.

\subsection{Hypothesis development}

Huvila (2010) has studied how corporate finance professionals' preferences with respect to information sources are related to their perceptions of success. He found that preference for specific information sources is related to particular measures of success. For example, market information and commissioned reports were considered to be useful when the profits of an organization were a key success measure for a respondent. The perceived importance of statistical information was related to measuring success in terms of short-term organizational outcomes. Conferences seemed to function as a useful information source that contribute to personal performance and effectiveness of work, for increasing personal influence and functioning as a venue of obtaining feedback. Professional journals were considered as a similarly versatile source of information that correlated with the quality of work, personal and organizational efficiency, and personal influence. From the perspective of this study, the most interesting findings were that browsing and the use of online financial news services, courses, and memos was related to how well private life and work are reconciled, and that in general, information sources that suggest an extensive IB (browsing, contacts, professional journals, conferences) tended to be correlated with personal rather than external measures of success.

On the basis of the earlier literature reviewed above, holistic information behavioral preferences can be presumed to be related to how individuals perceive their work success. Firstly, the breadth versus narrowness of information seeking styles and how they are linked to differences in how individuals manage and seek information (Heinström, 2006b) suggest that breadth versus narrowness of information behavioral orientation may have implications to other preferences as well. Secondly, on the basis of the findings of Huvila (2010) that preferred information sources and success measures are related, it seems plausible to assume that also information behavioral orientation might be similarly linked.

Hypothesis1. Holistic information behavior positively influences perceived success.

\section{Methodology}

\subsection{Data}

The data for this study was collected through a survey conducted in 2015 in a multinational organization that has operations in more than 50 countries around the world. The organization operates in the marine and energy industry. It develops high-tech energy products such as power engines and turbines. It also provides various kinds of services aimed at efficient management and maintenance of power systems operating on land and water.

To collect the data, a questionnaire was distributed through the company's internal survey system over the intranet. The absence of list of all the organizational employees (due to privacy 
concerns) meant that there was not a clear sampling frame. A convenience-sampling approach commonly used in many previous studies when a sampling frame is not accessible was adopted (Elbanna, Child \& Dayan, 2013). The survey was available to all organizational employees. Participation in the survey was voluntary. The survey was online for five weeks. During this time, the communication department of the organization advertised the survey through various internal channels such as e-mail and newsletter. At the end of the month, 305 useable responses were received. There were 378 missing values, which accounts for around 6 percent of the total values in the dataset. As recommended by Hair, Hult, Ringle, \& Sarstedt (2016), mean imputation was used; this is an appropriate approach to deal with a low number of missing values in a dataset. The demographic characteristics of the respondents are shown in Table 1.

Table 1. Demographic profile of respondents

\begin{tabular}{lll}
\hline Variable & Category & \% of respondents \\
\hline Age & $18-29$ & 20 \\
& $30-39$ & 38 \\
& $40-49$ & 28 \\
& $50-59$ & 13 \\
Gender & $60 \&$ above & 1 \\
& Male & 66 \\
Hierarchal level & Female & 34 \\
& Top & 12 \\
Continent & Middle & 32 \\
& Lower & 56 \\
& Africa & 1 \\
& Asia & 16 \\
& Europe & 72 \\
& North America & 4 \\
& South America & 7 \\
\hline
\end{tabular}

For path modeling, a sample size of 100-200 is usually considered adequate (Hoyle, 1995). Another way to determine sufficient sample size is by identifying the number of arrows leading to a latent variable and then multiplying it by 10 (Amaro \& Duarte, 2015). In the present study, there are seven endogenous constructs instead of one, resulting in seven incoming arrows, which means the sample size far exceeds the suitable limit of sample size for partial least squares modeling (PLS).

Common method variance can influence the results of PLS (Klarner, Sarstedt, Hoeck, \& Ringle, 2013). Therefore, common method variance was tested for using Harman's single factor test (Harman 1976; Podsakoff \& Organ, 1986). The first factor, extracted using principal axis factoring, without rotation, accounted for only $31 \%$ of the overall variance. It shows that common method variance is unlikely to be an issue, and therefore the analysis could proceed (Klarner et al., 2013; Podsakoff \& Organ, 1986). 


\subsection{Measures}

There are two main concepts in this study: holistic information behavior (IB) that consists of two dimensions, and perceived success that is here represented by eight different facets of success. In total, there are 10 measured constructs. All the constructs in the survey were measured using multiple items. A 7-point Likert scale ranging from 1 (strongly disagree) to 7 (strongly agree) was used. The questionnaire consisted of two sections. The first section contained questions regarding the demographic characteristics such as age, education and gender of the respondents. The second section contained questions about scale items that were used for measuring constructs. The previous scales and literature were used to measure the constructs.

Holistic IB is operationalized as a higher-order construct with two dimensions: individuals' openness, and self-development and understanding. A hierarchical or multidimensional construct is a construct with more than one dimension, where the dimensions are distinct yet related in a way that each dimension captures some portion of the overall latent variable (Akter, D'Ambra, \& Rey, 2011, Edwards, 2001; Jarvis, MacKenzie, \& Podsakoff, 2003; Petter, Straub, \& Rai, 2007). The use of the higher order multidimensional constructs has the advantage of theoretical parsimony and model simplicity as compared to lower order unidimensional constructs, particularly when the overall model contains many constructs (Edwards, 2001; MacKenzie, Podsakoff, \& Jarvis, 2005; Wetzels, Odekerken-Schröder, \& Van Oppen, 2009).

The findings of earlier IB research and especially the theorizing of Widén-Wulff et al. (2008) on the effects of relational versus structural social capital, lead to the proposal presented here that holistic IB can be measured as a product of individuals' openness towards seeking input and providing output (versus orientation towards acting in a small world) and their orientation towards broader exploitation of information through self-development and understanding beyond immediate instrumental task and context specific needs. Based on Liu's (2017) work, the proposed holistic IB can also be seen as an orientation towards long-term information demand (or, broader, use), or in the context of classical IB models and their derivatives (e.g. Wilson, 1997; Ellis, 1993; Rhee, 2012; Robson \& Robinson, 2013), information practices that go beyond a single seeking and use cycle in a specific context and stretch out to the lifeworld (Burnett, 2015; Jaeger \& Burnett, 2010) of the individual.

Following Beck et al. (2012), holistic IB was operationalized as a reflective-formative higher order construct, which means change in the lower order constructs (openness, and selfdevelopment and understanding) will lead to a change in the higher order construct (holistic IB). The repeated indicator approach was employed to measure the holistic IB (Lohmöller, 1989). More specifically, the indicators that measured openness, and self-development and understanding were used together to form holistic IB. The repeated indicator approach has been found very useful for the operationalization of hierarchal constructs as it provides better estimates and reliable higher order constructs (Amaro \& Duarte, 2015; Becker et al, 2012). 
Perceived success refers to individuals' perceptual and objective evaluations of, and reactions to, success at work (Greenhaus et al., 1990; Ng \& Feldman, 2014; Turban \& Dougherty, 1994). According to Gattiker and Larwoods (1986), perceived success is a multifaceted concept. They have identified work role-related success, interpersonal success, financial success, hierarchal success and productivity success. Many other studies have identified and operationalized additional facets of success (Clark \& Arnold, 2008; Dyke \& Murphy, 2006; Heslin, 2005; Ng \& Feldman, 2014; Sturges, 1999). In line with the previous research, a multifaceted view of the perceived success is adopted. Perceived success is measured in terms of operational performance, organizational accomplishment, external organizational feedback (from outside of the organization), internal feedback (from the organization to the individual), personal performance, personal development, control over work and monetary achievement (Table 2). Respondents were asked about their perceived importance of the measures of success. These measures were developed on the basis of the questionnaires used by Orser and Dyke (2005) and Huvila (2010), with the scales from the studies of Peluchette and Jeanquart (2000), and Walker and Brown (2004) as references. The measurement items are shown in Appendix 1.

Table 2. Facets of success

\begin{tabular}{ll}
\hline Latent constructs & Definitions \\
\hline Operational performance & How effectively and well the organization currently operates. \\
Accomplishment potential & How well the organization can be expected to perform in the short and \\
& long term. \\
Positive/negative feedback from actors that are external to the organization & (customers, external evaluators, general public). \\
External organizational feedback & Positive/negative feedback from within the organization (colleagues, \\
Internal feedback & superiors). \\
& How well the respondent feels (s)he does his/her job. \\
Personal performance & Personal learning and insights. \\
Personal development & Influence on one's own work duties, joy of work, reconciliation of work \\
Control over work & and private life. \\
& Salary and benefits. \\
\hline
\end{tabular}

Partial least square structural equation modeling (PLS-SEM) was used to validate the measures and for data analysis. PLS-SEM is a second-generation statistical technique whose application has been widespread in recent years (Hair, Ringle, \& Sarstedt, 2011; Wong, 2013). This technique is particularly suitable for the data analysis when a multidimensional construct is employed, as is the case in this study (Becker et al., 2012; Lowry \& Gaskin, 2014). Moreover, this method has less restrictive assumptions about the data. For example, it can handle the small sample size and non-normally distributed data-it applies the non-parametric bootstrapping (Davison \& Hinkley, 1997; Hair et al., 2011; Lowry \& Gaskin, 2014). Moreover, constructs containing fewer than three indicators can also be used (Amaro \& Duarte, 2015). In this study, there are four constructs with only two indicators. This further supports the suitability of this method for data analysis in this study. 
Smart PLS was used to compute the path model. The path weighting scheme was used for parameter estimation. In the analysis and interpretation of the data, guidelines given by Becker et al. (2012) and Hair et al. (2016) were followed. Consequently, the measurement model was evaluated before the structural model.

\section{Results}

\subsection{The measurement model}

In PLS, a reflective measurement model is assessed for constructs' reliability (indicator reliability and consistency reliability) and validity (convergent validity and discriminant validity). The procedure to assess the quality of formative constructs is different and therefore will be discussed later.

As shown in Table 3, Cronbach's alpha values of all constructs are above the required threshold value of 0.70 (Hair, Black, Babin, \& Anderson, 2010). Some researchers argue that composite reliability is more suitable for assessing reliability in PLS than Cronbach's alpha (Henseler, Ringle, \& Sinkovics, 2009). Therefore, Hair et al., (2016) proposes reporting both Cronbach's alpha and composite reliability. The composite reliability of the constructs range from 0.85 to 0.97, which exceeds the recommended limit of 0.70 (Bagozzi \& Yi, 1988). Finally, all the indicator loadings are above the cutoff value of 0.60 , which further establishes the reliability of the constructs used in the study (Chin, 1998).

Table 3. Measurement statistics of construct scales based on reflective indicators

\begin{tabular}{|c|c|c|c|c|c|c|}
\hline Construct and indicators & Mean & $\begin{array}{l}\text { Standard } \\
\text { deviation }\end{array}$ & $\begin{array}{l}\text { Indicator } \\
\text { loadings }\end{array}$ & $\begin{array}{l}\text { Composite } \\
\text { reliability }\end{array}$ & Cronbach's $\alpha$ & AVE \\
\hline Openness & 5.88 & 0.78 & & 0.85 & 0.76 & 0.58 \\
\hline OP1 & & & 0.80 & & & \\
\hline OP2 & & & 0.77 & & & \\
\hline OP3 & & & 0.76 & & & \\
\hline $\mathrm{OP} 4$ & & & 0.72 & & & \\
\hline Self-development \& & & & & & & \\
\hline understanding & 5.93 & 0.82 & & 0.87 & 0.78 & 0.69 \\
\hline SDU1 & & & 0.84 & & & \\
\hline SDU2 & & & 0.79 & & & \\
\hline SDU3 & & & 0.86 & & & \\
\hline Operational performance & 5.46 & 1.12 & & 0.97 & 0.93 & 0.94 \\
\hline OP1 & & & 0.97 & & & \\
\hline OP2 & & & 0.96 & & & \\
\hline Accomplishment potential & 5.12 & 1.08 & & 0.91 & 0.86 & 0.78 \\
\hline AP1 & & & 0.89 & & & \\
\hline AP2 & & & 0.89 & & & \\
\hline AP3 & & & 0.87 & & & \\
\hline $\begin{array}{l}\text { External organizational } \\
\text { feedback }\end{array}$ & 4.98 & 1.15 & & 0.86 & 0.77 & 0.68 \\
\hline EOF1 & & & 0.85 & & & \\
\hline
\end{tabular}




\begin{tabular}{|c|c|c|c|c|c|c|}
\hline \multirow{2}{*}{\multicolumn{3}{|c|}{$\begin{array}{l}\text { EOF2 } \\
\text { EOF3 }\end{array}$}} & \multicolumn{4}{|l|}{0.82} \\
\hline & & & 0.79 & & & \\
\hline Internal feedback & 5.82 & 0.88 & & 0.91 & 0.82 & 0.84 \\
\hline IF 1 & & & 0.90 & & & \\
\hline IF2 & & & 0.94 & & & \\
\hline Personal performance & 5.90 & 0.90 & & 0.97 & 0.94 & 0.95 \\
\hline PP1 & & & 0.97 & & & \\
\hline PP2 & & & 0.98 & & & \\
\hline Personal development & 5.56 & 0.91 & & 0.86 & 0.76 & 0.67 \\
\hline PD1 & & & 0.86 & & & \\
\hline PD2 & & & 0.81 & & & \\
\hline PD3 & & & 0.77 & & & \\
\hline Control over work & 5.58 & 0.93 & & 0.89 & 0.81 & 0.72 \\
\hline COW1 & & & 0.85 & & & \\
\hline COW2 & & & 0.89 & & & \\
\hline COW3 & & & 0.82 & & & \\
\hline Monetary achievement & 4.63 & 1.43 & & 0.90 & 0.95 & 0.82 \\
\hline MA1 & & & 0.99 & & & \\
\hline MA2 & & & 0.82 & & & \\
\hline
\end{tabular}

Convergent validity is assessed by calculating the AVE value of each construct (Fornell \& Larcker, 1981). The result (Table 3) supports the convergent validity as the AVE value of all constructs is above the recommended value of 0.50 (Amaro \& Duarte, 2015; Hair et al., 2016).

Discriminant validity was assessed via two methods. According to the Fornell and Larcker criterion (1981), discriminant validity can be assessed by comparing the average variance extracted of each construct with the correlation among constructs (Wong, 2013). Table 4 shows the correlation coefficients in the off-diagonal elements of the matrix and the square roots of each construct's AVE along the diagonal. The bold values along the diagonal are greater than all respective rows and columns, which fulfills the Fornell-Larcker criterion. Another way to assess the discriminant validity is to look at the cross loadings of the indicators on different constructs (Hair et al., 2016). Each indicator should load on its respective construct without having stronger relation with other constructs (Amaro \& Duarte, 2015; Hair et al., 2016). No cross-loadings were found in the data. Both analyses show that all the constructs in this study have adequate discriminant validity.

Table 4. Discriminant validity of the constructs: Correlations between constructs

\begin{tabular}{lllllllllll}
\hline & 1 & 2 & 3 & 4 & 5 & 6 & 7 & 8 & 9 & 10 \\
\hline Accomplishment potential & $\mathbf{0 . 8 8}$ & & & & & & & & & \\
Control over work & 0.38 & $\mathbf{0 . 8 5}$ & & & & & & & & \\
$\begin{array}{l}\text { External organizational } \\
\text { feedback }\end{array}$ & 0.46 & 0.38 & $\mathbf{0 . 8 2}$ & & & & & & & \\
& & & & & & & & & & \\
\end{tabular}




\begin{tabular}{lllllllllllll} 
Internal feedback & 0.28 & 0.47 & 0.52 & $\mathbf{0 . 9 2}$ & & & & & & \\
Monetary achievement & 0.24 & 0.44 & 0.26 & 0.21 & $\mathbf{0 . 9 1}$ & & & & & \\
Operational performance & 0.55 & 0.41 & 0.54 & 0.49 & 0.26 & $\mathbf{0 . 9 7}$ & & & & \\
Openness & 0.16 & 0.30 & 0.20 & 0.32 & - & 0.19 & $\mathbf{0 . 7 6}$ & & & \\
& & & & & 0.03 & & & & & \\
Personal development & 0.40 & 0.76 & 0.44 & 0.50 & 0.42 & 0.46 & 0.33 & $\mathbf{0 . 8 2}$ & & \\
Personal performance & 0.31 & 0.59 & 0.41 & 0.57 & 0.18 & 0.42 & 0.35 & 0.72 & $\mathbf{0 . 9 7}$ & \\
Self-development \& & 0.15 & 0.26 & 0.16 & 0.26 & - & 0.21 & 0.59 & 0.32 & 0.27 & $\mathbf{0 . 8 3}$ \\
understanding & & & & & 0.03 & & & & & \\
\hline Bo
\end{tabular}

Bold numbers represent the square roots of the AVEs.

As far as the quality of the formative construct (holistic IB) is concerned, Becker et al. (2012), suggests assessing the weights of the first order (dimensions) constructs on the second order (multidimensional) construct and their significance levels. This shows whether the first order constructs contribute to form the second order construct or not. The weights of the two first-order constructs, openness and self-development and understanding were 0.69 and 0.40 respectively. Both were significant, demonstrating a sufficient level of validity.

\subsection{Structural model}

After assessing the measurement model, the relationship between constructs was analyzed by standardized path coefficients and significance levels. The results are presented in Figure 1.

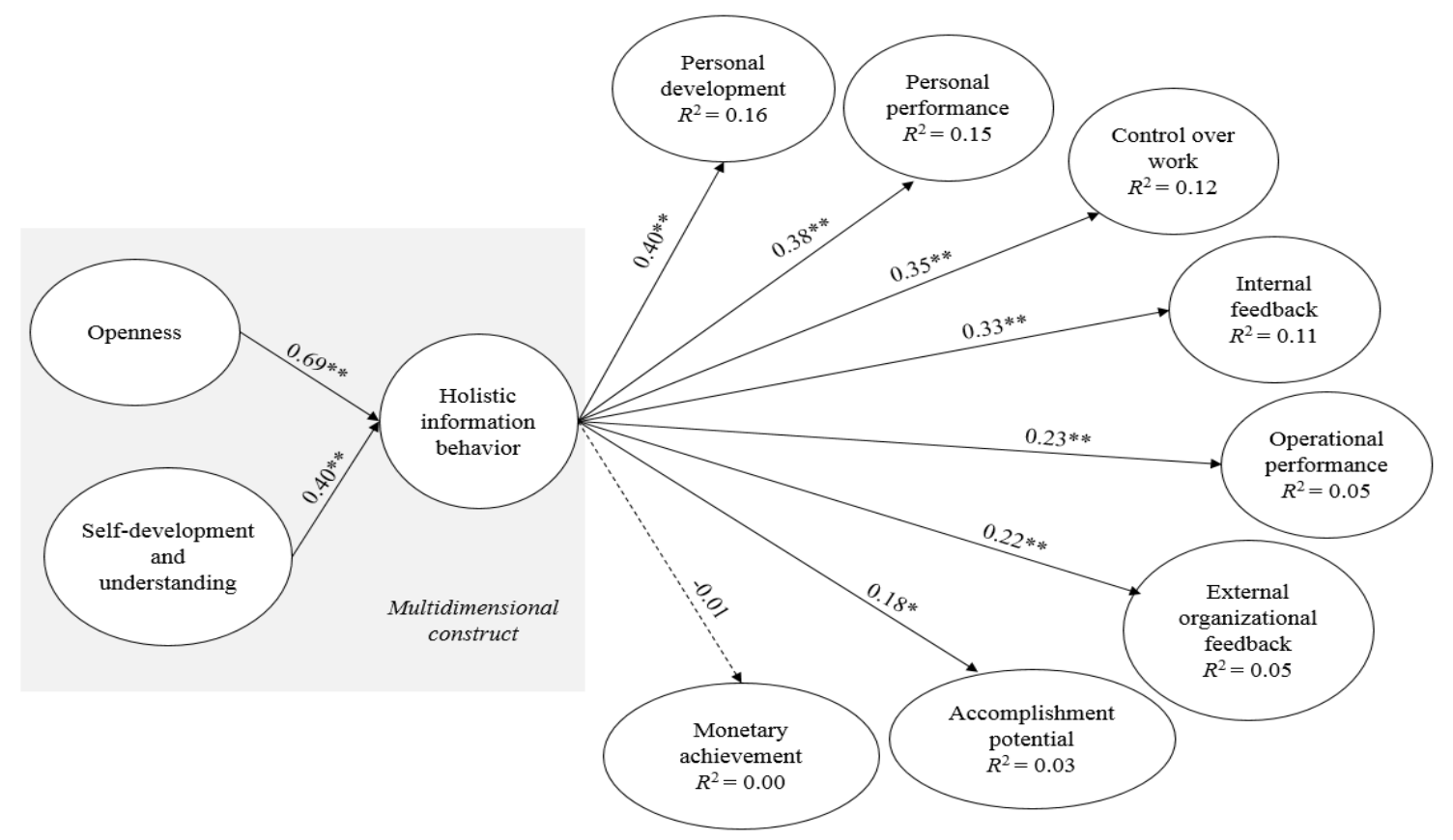

Figure 1. PLS analysis results

Notes:

$* p<0.05$ (two-sided test) 
** $p<0.01$ (two-sided test)

Dashed line indicates non-significant path relation

The hypothesis that holistic information behavior positively influences the perception of success is mostly confirmed as holistic information behavior has a significant effect on all the facets of success except the monetary achievement $(\beta=-0.015, p=0.845)$. In terms of the strength of the effect, holistic information behavior has the strongest influence on success in personal development $(\beta=0.40, p=0.00)$ followed by personal performance $(\beta=0.38, p=0.00)$, control over work $(\beta=0.35, p=0.00)$ and internal feedback $(\beta=0.33, p=0.00)$. Although holistic IB also influences the perception of success in terms of operational performance $(\beta=0.23, p=0.00)$, external organizational feedback $(\beta=0.22, \mathrm{p}=0.00)$ and accomplishment potential $(\beta=0.18, \mathrm{p}=$ 0.02 ), the strength of the relationships is weaker as compared to other success factors.

\section{Discussion}

The findings show that holistic IB is related to multiple facets of success. In general, the facets with the strongest relation to holistic IB can be described as being more closely and diversely knitted to the context of a person's life-world. They are also closer to an individuals' own experience by being oriented towards interaction and exchange rather than external and remote facets like economic rewards or organizational performance, which are influenced less by individual achievements than by external and difficult-to-anticipate effects, as could be expected.

Consistent with what could be expected, orientation towards openness, self-development and understanding, which together form holistic IB, has the strongest effect on analogous facets of success of personal development, personal performance and control over work. This resonates well with the earlier findings of Huvila (2010) of the related preference of cross-boundary and general purpose information sources (e.g., browsing, news, courses, memos) and personal rather than external facets of success. The finding links also to Choo's (2016) congruence hypothesis in that information culture and criteria of success are indeed linked to each other. Even if the stronger effect of internal (versus external) feedback may appear contradictory in light of the model of Widén-Wulff and colleagues (2008), the significance of openness for feedback from colleagues and superiors can be plausibly interpreted as an expression of openness to and importance of feedback from knowledgeable stakeholders of work rather than as direct evidence of reticence. The finding does, however, also point to the paradox of the parallel benefits and disadvantages of close-knit communities and reaching out of small worlds (Huotari \& Chatman, 2001), and the difficulty of drawing boundaries around contexts that tend to be overlapping rather than isolated, as portrayed in the work of Chatman (Burnett, 2015).

The negative effect of holistic IB on monetary value can be understood in light of the lack of sophistication of economic rewards as a measure of success criticized in earlier literature on work success (Heslin, 2003). It seems plausible that a schematic idea of work success is more compatible with a narrow and focused IB than as a more holistic, life-world-wide orientation 
towards information activities.

The spread of effect of holistic IB on different success factors evince the multi-faceted nature of their relationship. Even if the findings of this study and earlier research (Huvila, 2010) both demonstrate that informational preferences and behaviors are related to different perceptions of success of work, as the literature review showed, there are multiple other factors that influence how individuals assess the success of their efforts. This is also a major limitation of the current study and consequently an urge for future research to investigate the information behavior as a facet of perceived work success alongside other behavioral factors.

In addition to the implications for research on information behavior and perceived success, the proposed notion of holistic IB and the observations made on its connections to perceived work success informs information behavior research. It seems plausible to suggest that holism of IB is a similar factor to, for instance, time (Wilkinson et al., 2012), personality (Heinström, 2006b) and task complexity (Byström, 2000), that influences information activities. The present findings represent a small step towards the direction called for by Wilson (2009), that is, identifying possible causal variables that can be incorporated to IB models. Even if earlier information behavior research (Case \& Given, 2016; Krampen, 2011) has rather plainly demonstrated the possibilities "to develop generalizable explanations of behavioral phenomena observable when humans acquire and process information" (Browne et al., 2017, p.1), the present findings suggest that holism/aholism could be a factor with the potential to explain some of the variation of how people interact with information. It can be assumed that holistic information seekers would be inclined to choose deeper and more strategic approaches rather than surface-oriented approaches to finding information (cf. Heinström, 2006b). The relationship between information-seeking styles (Heinström, 2005) and holistic versus aholistic IB is an obvious topic for future research. The fact that Byström's (1999) findings on the task's complexity nudges people to use other people as information sources rather than turn to external sources is interesting from the perspective of holistic IB. Both Heinström's and Byström's studies raise the question of the need to study holistic IB in practical and naturalistic settings to see how self-reported preferences correlate with actual behavior in context. An evident follow-up question is whether, for instance, the promotion of particular types of (e.g., economic) facets of success can be factors that make people deviate from purportedly more natural holistic information behavior (Bates, 2002, 2007; Pirolli \& Card, 1999) to become more focused. Earlier information research, including the observations of Jaeger and Burnett (2010), Blandford and Attfield (2010), and Byström (2000), suggest that mutiple factors can pivot information activities.

Another interesting point of discussion about holistic versus aholistic IB relates to the question of relevance (Saracevic, 2016) of information. The observation that holistic IB has an effect on the perception of success raises a question about the variance of the perceived relevance of specific types of information resources in the context of holistic IB. Huvila's (2010) work shows that the preference for, and as a consequence, relevance, of particular types of information sources and 
preferred facets of success are related. Combined with the findings of the present study, it can be speculated that holistic and non-holistic IB are likely to have an effect on the perceptions of the relevance of particular types of information (sources).

One of the practical implications of the present study is that understanding how people work with information can help one to understand their idea of the success of their work. Holistic IB has far reaching implications for the organization. By promoting holistic IB, organizations can reap benefits that extend beyond improved perception of success. The results show that employees engaging in holistic information behavior are likely to perceive themselves as successful, particularly at the individual level. When employees perceive themselves to be successful at the individual level, they are further motivated to keep pursuing their goals, which will ultimately improve organizational performance (Reijonen \& Komppula, 2007). Holistic IB can play an important role in the transformation of individual performance into organizational performance by instigating a strong perception of success in employees.

Moreover, holistic IB can reduce employee turnover in organizations. Previous research has shown that employees feeling lack of accomplishment and worthiness at their job tend to consider alternative job options (Kim \& Stoner, 2008; Pierce \& Gardner, 2004). The development of positive perception of success through holistic information behavior can cultivate a positive experience of achievement and self-esteem, thereby reducing employees' desire to leave the organization.

In the light of the earlier suggestions of the positive impact of openness of IB on the innovation capability of individuals and organizations (Huotari \& Chatman, 2001; Huvila, 2010; Molyneux et al., 2015), promoting holistic IB through a focus on particular success facets could be used to spur innovativeness. This could include encouraging independent information seeking and use for personal development, evaluation of one's work performance, and planning one's own work, and by providing more and more detailed internal feedback to support these information activities. Correspondingly, it is conceivable that less holistic forms of IB could be promoted by nurturing economic incitements as preferred facets of work success if the aim is to turn work in a more focused and centrifugal direction. Employees could be, for instance, guided by promoting monetary or other formal rewards for effective meeting of management-defined goals. This could be beneficial in an environment where creativity can be more counter-productive than following pre-determined procedures. There are obvious problems with these propositions. Firstly, as processes relating to social capital at the workplace, they are difficult to (micro-)manage (Manning, 2010). Secondly, interventions that blur the temporal, economic, and social boundaries of (waged) work and (non-waged) non-work are not unproblematic as earlier research has pointed out (Gregg, 2011; Valcour \& Hunter, 2005). Similarly to how Fuller (2007) has criticized the notion of social capital turning a public good into a positional one (what matters is the social order to an individual possession), instrumental appropriation of individual perceptions of success and information behavior as a lifeworld-wide notion, to paraphrase Gregg (2011), risks 
interfering with the intimacy of success and information behavior.

\subsection{Limitations}

There are several limitations of this study. First, data were collected from a single multinational organization. The organizational culture specific to this organization can bias the observed relationships. Nevertheless, collection of data from different subsidiaries lowers such risk, as subsidiaries operate in different contexts and have different strategic roles which create variations in their methods of working and, consequently, their cultures. Second, cross-cultural differences were not consideted. Most of the respondents (72\%) come from the European continent, which has a high level of individualism. Individualistic cultures have a higher positive attitude toward personal achievement as compared to highly collectivist cultures (Kim, Park \& Suzuki, 1990; Schuler \& Rogocsky, 1998). It is conceivable that the results could be to some degree different in another type of organization with different employee demographics even if the pattern would persist. Third, the sample is male-dominant, mainly because the organization operates in the energy industry with a huge workforce of engineers. Future research, therefore, should extend the analysis to other industries with less gender asymmetry, such as the service industry. Fourth, the hierarchical level can influence perception of success. Individuals at a lower level of hierarchy may consider individual-related aspects of success to be more important than organizationalrelated aspects and vice versa. Multigroup analysis revealed that lower, middle, and upper management-level employees do not have any significant differences in the perception of success in relation to holistic IB. Nevertheless, this should be tested in future research more thoroughly, as group sizes in the multigroup analysis were unequal. Particularly, the top management group formed only $12 \%$ of the total sample, which, due to the small size, may result in biased multigroup analysis results (Hair et al., 2016). Finally, it seems apparent that the operationalization of the notion of holistic IB would benefit from future theoretical and empirical work and inclusion and refinement of its facets.

\section{Conclusion}

The findings of this study show that holistic IB is related to a comparably holistic lifeworld-wide conceptualization of success. The facets of success are also closer to an individuals' own experience by being oriented towards interaction and exchange rather than external and remote facets like economic rewards or organizational performance. From the perspective of IB research, the findings suggest that holism seems to be a similar factor to, for instance, task complexity or personality, which influences human IB. The analysis also suggests that the holism of IB can have an impact on the perceptions of relevance.

As a practical implication of these results, it should be possible to influence how employees measure the success of their work by promoting interaction and exchange-oriented IB. Promoting holistic IB through openness and self-development and understanding will affect organizational performance and employees' commitment. Correspondingly, it is conceivable that less holistic and simultaneously less natural forms of information behavior could be promoted by nurturing 
economic incitements as preferred measures of work success if the aim is to make work more centrifugal.

\section{Acknowledgement}

This research has been partially funded by the Academy of Finland grant 295743 for the project 'The Impact of Information Literacy in the Digital Workplace'.

\section{Appendix 1}

\section{Measurement items}

\section{Holistic information behavior}

\section{Openness}

Item 1 It is important to critically reflect what is important for my success in my work and be open to new approaches.

Item 2 It is important for success in my work to be knowledgeable about the people who are not from my own department (e.g., customers, colleagues, competitors).

Item 3 I communicate with different types of people (e.g., with diverse positions, nationalities, characters, education, social class) in my work.

Item 4 As a part of my work, it is satisfying to be able to help others solve their problems, even if it would not directly be my responsibility.

Self-development \& understanding

Learning in my work is important for me:

Item 1 If it helps me to succeed in my life, even if it would not help me at my current work.

Item 2 Because it helps me to understand and develop my work and working.

Item 3 Even if the things I have learned would not be directly linked to my work success at present.

\section{Success factors}

The following factors indicate that I have been successful in my work;

Operational performance

Item 1 Quality of operations

Item 2 Efficiency of operations

Accomplishment potential

Item 1 Realization of organizational goals

Item 2 Increased organizational success potential in the long run

Item 3 Expected organizational success in the near future

External organizational feedback

Item 1 Feedback from external evaluators

Item 2 Feedback/opinions from the public

Item 3 Customer feedback (broadly)

Internal feedback (to the individual)

Item 1 Feedback from colleagues

Item 2 Feedback from superiors

Personal performance 


\begin{tabular}{ll}
\hline Item 1 & Effectiveness of own work \\
Item 2 & Efficiency of own work \\
Personal & development \\
Item 1 & Career record \\
Item 2 & Personal learning \\
Item 3 & Self-confidence of success \\
Control & over work \\
Item 1 & Influence on my own work duties \\
Item 2 & Joy of work \\
Item 3 & Reconciliation of work and private life \\
Monetary & achievement \\
Item 1 & Salary \\
Item 2 & Benefits
\end{tabular}

\section{References}

Abrahamson, D. E., \& Goodman-Delahunty, J. (2013). The impact of organizational information culture on information use outcomes in policing: An exploratory study. Information Research, 19(4). Retrieved from http://www.informationr.net/ir/18-4/paper598.html

Agarwal, N. K. (2017). Exploring context in information behavior: Seeker, situation, surroundings, and shared identities. San Rafael, CA: Morgan \& Claypool.

Ahmad, F., \& Widén, G. (2015). Language clustering and knowledge sharing in multilingual organizations: A social perspective on language. Journal of Information Science, 41, 430443.

Akter, S., D'Ambra, J., \& Ray, P. (2011). Trustworthiness in mHealth information services: An assessment of a hierarchical model with mediating and moderating effects using partial least squares (PLS). Journal of the Association for Information Science and Technology, $62,100-116$.

Allen, D. K., \& Shoard, M. (2005). Spreading the load: Mobile information and communications technologies and their effect on information overload. Information Research, 10(2). Retrieved from http://www.informationr.net/ir/10-2/paper227.html

Amaro, S., \& Duarte, P. (2015). An integrative model of consumers' intentions to purchase travel online. Tourism management, 46, 64-79.

Bagozzi, R. P., \& Yi, Y. (1988). On the evaluation of structural equation models. Journal of the Academy of Marketing Science, 16(1), 74-94.

Bak, P., \& Meyer, J. (2011). The effect of user characteristics on the efficiency of visual querying. Behaviour \& Information Technology, 30, 809-819.

Bates, M. J. (2002). Toward an integrated model of information seeking and searching. The New Review of Information Behaviour Research, 3, 1-15.

Bates, M. J. (2007). What is browsing - really? A model drawing from behavioural science research. Information Research, 12(4). Retrieved from http://www.informationr.net/ir/124/paper330.html

Becker, J. M., Klein, K., \& Wetzels, M. (2012). Hierarchical latent variable models in PLS-SEM: guidelines for using reflective-formative type models. Long Range Planning, 45(5-6), 359-394.

Belkin, N. J., Oddy, R. N., \& Brooks, H. M. (1982). ASK for information retrieval: Part I. Background and theory. Journal of Documentation, 38, 61-71. 
Benzing, C., Chu, H. M., \& Kara, O. (2009). Entrepreneurs in Turkey: A factor analysis of motivations, success factors, and problems. Journal of Small Business Management, 47(1), 58-91. http://dx.doi.org/10.1111/j.1540-627X.2008.00262.x

Bergeron, P., Heaton, L., Choo, C. W., Detlor, B., Bouchard, D., \& Paquette, S. (2007). Knowledge and information management practices in knowledge-intensive organizations: A case study of a Québec public organization. In C. Arsenault \& K. Dalkir (Eds.), Information sharing in a fragmented world: Crossing boundaries. Canadian Association for Information Science (CAIS/ACSI) 35th Annual Conference, McGill University, Montreal, Quebec, May 10-12, 2007. Retrieved from https://journals.library.ualberta.ca/ojs.cais-acsi.ca/index.php/caisasci/article/view/200/162

Beyene, W. M., \& Byström, K. (2017). Rethinking information behavior in the context of universal design. In S. Wjatscheslaw (Ed.), Effect, expand, evolve: Global collaboration across the information community. Proceedings of the 2017 iConference, March 22-25, Wuhan, China (pp. 216-226). Retrieved from http://hdl.handle.net/2142/96674

Blandford, A., \& Attfield, S. (2010). Interacting with information. San Rafael, CA: Morgan and Claypool.

Boudreau, J., Boswell, W., \& Judge, T. (2001). Effects of personality on executive career success in the United States and Europe. Journal of Vocational Behavior, 58, 53-81.

Bowen, P. L., Ferguson, C. B., Lehmann, T. H., \& Rohde, F. H. (2003). Cognitive style factors affecting database query performance. International Journal of Accounting Information Systems, 4(4), 251-273.

Bronstein, J. (2007). The role of the research phase in information seeking behaviour of Jewish studies scholars: A modification of Ellis's behavioural characteristics. Information Research, 12(3). Retrieved from http://www.informationr.net/ir/12-3/paper318.html

Browne, G. J., Cheung, C. M. K., Heinzl, A., \& Riedl, R. (2017). Human information behavior. Business \& Information Systems Engineering, 59(1), 1-2.

Buchanan, S., \& Tuckerman, L. (2016). The information behaviours of disadvantaged and disengaged adolescents. Journal of Documentation, 72, 527-548.

Burford, S., \& Park, S. (2014). The impact of mobile tablet devices on human information behavior. Journal of Documentation, 70, 622-639.

Burnett, G. (2015). Information worlds and interpretive practices: Toward an integration of domains. Journal of Information Science Theory and Practice, 3(3), 6-16.

Burnett, G., \& Erdelez, S. (2010). Forecasting the next 10 years in information behavior research: A fish bowl dialogue. Bulletin of ASIS\&T, 36(3), 44-48.

Byström, K. (1999). Task complexity, information types and information sources (Unpublished doctoral dissertation). University of Tampere, Finland.

Byström, K. (2000). The effects of task complexity on the relationship between information types acquired and information sources used. The New Review of Information Behaviour Research, 1, 85-101.

Capra, R., Khanova, J., \& Ramdeen, S. (2013). Work and personal e-mail use by university employees: PIM practices across domain boundaries. Journal of the American Society for Information Science \& Technology, 64, 1029-1044.

Case, D. O., \& Given, L. M. (2016). Looking for information: A survey of research on information seeking, needs, and behavior. Bingley, England: Emerald.

Chatman, E. A. (1991). Life in a small world: Applicability of gratification theory to informationseeking behavior. Journal of the American Society for Information Science, 42, 438-449.

Chatman, E.A. (1999). A theory of life in the round. Journal of the American Society for Information Science, 50, 207-217. 
Chin, W. W. (1998). Commentary: issues and opinion on structural equation modeling. MIS Quarterly, 22(1), vii-xvi.

Choo, C. W. (1996). The knowing organization: How organizations use information to construct meaning, create knowledge and make decisions. International Journal of Information Management, 16, 329-340.

Choo, C. W. (2016). The inquiring organization: How organizations acquire knowledge and seek information. Oxford University Press.

Choo, C. W., Bergeron, P., Detlor, B., \& Heaton, L. (2008). Information culture and information use: An exploratory study of three organizations. Journal of the American Society for Information Science \& Technology, 59, 792-804.

Clark, M., \& Arnold, J. (2008). The nature, prevalence and correlates of generativity among men in middle career. Journal of Vocational Behavior, 73(3), 473-484.

Cooper, A. C., \& Artz, K. W. (1995). Determinants of satisfaction for entrepreneurs. Journal of Business Venturing, 10(6), 439 - 457.

Dankasa, J. (2016). Mapping the everyday life information needs of catholic clergy: Savolainen's ELIS model revisited. Journal of Documentation, 72, 549-568.

Dann, S. (1995). Gender differences in self-perceived success. Women in Management Review, 10(8), 11-18.

Davison, A. C., \& Hinkley, D. V. (1997). Bootstrap methods and their application. Cambridge, England: Cambridge University Press.

Dervin, B. (1998). Sense-making theory and practice: An overview of user interests in knowledge seeking and use. Journal of Knowledge Management, 2(2), 36-46.

Di Vincenzo, F., Hemphälä, J., Magnusson, M., \& Mascia, D. (2012). Exploring the role of structural holes in learning: an empirical study of Swedish pharmacies. Journal of Knowledge Management, 16(4), 576-591.

Dörk, M., Carpendale, S., \& Williamson, C. (2011). The information flaneur: A fresh look at information seeking. Annual CHI Conference on Human Factors in Computing Systems, 29. Retrieved from http://mariandoerk.de/informationflaneur/chi2011.pdf

Dyke, L. S., \& Murphy, S. A. (2006). How we define success: A qualitative study of what matters most to women and men. Sex Roles, 55(5-6), 357-371.

Edwards, J. R. (2001). Multidimensional constructs in organizational behavior research: An integrative analytical framework. Organizational Research Methods 4(2), 144-192.

Elbanna, S., Child, J., \& Dayan, M. (2013). A model of antecedents and consequences of intuition in strategic decision-making: Evidence from Egypt. Long Range Planning, 46(12), 149-176.

Ellis, D. (1993). Modeling the information-seeking patterns of academic researchers. Library Quarterly, 63, 469-486.

Erickson, J. J., Martinengo, G., \& Hill, E. J. (2010). Putting work and family experiences in context: Differences by family life stage. Human Relations, 63(7), 955-979.

Fenwick, T., \& Hutton, S. (2000). Women crafting new work: The learning of women entrepreneurs. Proceedings of the Annual Adult Education Research Conference, 41. Retrieved from http://newprairiepress.org/cgi/viewcontent.cgi?article $=2162 \&$ context $=$ aerc

Ferran-Ferrer, N., Minguillón, J., \& Pérez-Montoro, M. (2013). Key factors in the transfer of information-related competencies between academic, workplace, and daily life contexts. Journal of the American Society for Information Science \& Technology, 64, 1112-1121.

Fornell, C., \& Larcker, D. F. (1981). Structural equation models with unobservable variables and measurement error: Algebra and statistics. Journal of marketing research, 382-388.

Foster, A. (2004). A nonlinear model of information-seeking behavior. Journal of the American 
Society for Information Science \& Technology, 55, 228-237.

Foster, A. E., \& Urquhart, C. (2012). Modelling nonlinear information behaviour: Transferability and progression. Journal of Documentation, 68, 784-805.

Fuller, S. (2007). The knowledge book: Key concepts in philosophy, science, and culture. Stocksfield, England: Acumen. Retrieved from http://site.ebrary.com/id/10455598

Furnham, A., Trickey, G., \& Hyde, G. (2012). Bright aspects to dark side traits: Dark side traits associated with work success. Personality and Individual Differences, 52(8), 908-913.

Gattiker, U. E., \& Larwood, L. (1986). Subjective career success: A study of managers and support personnel. Journal of business and psychology, 1(2), 78-94.

Gerber, P. J. (2002). Navigating the beyond-school years: Employment and success for adults with learning disabilities. Career Planning and Adult Development Journal, 18(1), 136144.

Ginman, M. (1988). Information culture and business performance. IATUL Quarterly, 2(2), 93 106.

Goodale, P., Clough, P. D., Fernando, S., Ford, N., \& Stevenson, M. (2014). Cognitive styles within an exploratory search system for digital libraries. Journal of Documentation, 70, 970-996.

Greenhaus, J. H., Parasuraman, S., \& Wormley, W. M. (1990). Effects of race on organizational experiences, job performance evaluations, and career outcomes. Academy of Management Journal, 33(1), 64-86.

Gregg, M. (2011). Work's intimacy. Cambridge, England: Polity.

Hair J. F., Jr., Hult, G. T. M., Ringle, C., \& Sarstedt, M. (2016). A primer on partial least squares structural equation modeling (PLS-SEM) (2d ed.). Los Angeles, CA: SAGE.

Hair, J. F., Jr., Black,W. C., Babin, H. J., \& Anderson, R. E. (2010). Multivariate data analysis (7th ed.). Upper Saddle River, NJ: Prentice Hall.

Hair, J. F., Jr., Ringle, C. M., \& Sarstedt, M. (2011). PLS-SEM: Indeed a silver bullet. Journal of Marketing Theory and Practice, 19(2), 139-152.

Hall, H., \& Widén-Wulff, G. (2008). Social exchange, social capital and information sharing in online environments: Lessons from three case studies. In M.-L. Huotari, \& E. Davenport (Eds.) From information provision to knowledge production: Proceedings of the International Conference for the Celebration of the $20^{\text {th }}$ Anniversary of Information Studies, Faculty of Humanities, University of Oulu, Finland, June 23-25, 2008 (pp. 7386). Oulu, Finland: Oulu University Press.

Harman, H.H. (1976). Modern factor analysis. Chicago, IL: University of Chicago Press

Heinström, J. (2005). Fast surfing, broad scanning and deep diving: The influence of personality and study approach on students' information-seeking behavior. Journal of Documentation, 61, 228-247.

Heinström, J. (2006a). Broad exploration or precise specificity: Two basic information seeking patterns among students. Journal of the American Society for Information Science \& Technology, 57(11), 1440-1450.

Heinström, J. (2006b). Fast surfing for availability or deep diving into quality: Motivation and information seeking among middle and high school students. Information Research, 11(4). Retrieved from http://www.informationr.net/ir/11-4/paper265.html

Heinström, J., Huvila, I., Widén, G., \& Ahmad, F. (2014, November). A multi-perspective framework for knowledge sharing research. Paper presented at the 10th International Conference on Knowledge Management (ICKM), Antalya, Turkey, November 24-26, 2014.

Henseler, J., Ringle, C. M., \& Sinkovics, R. R. (2009). The use of partial least squares path modeling in international marketing. Advances in International Marketing, 20(1), 277- 
319.

Heslin, P. (2003). Self- and other-referent criteria of career success. Journal of Career Assessment, 11(3), 262-286.

Heslin, P. (2005). Conceptualizing and evaluating career success. Journal of Organizational Behavior, 26(2), 113-136.

Hoyle, R. H. (1995). Structural equation modeling: Concepts, issues, and applications. Sage.

Hudson, M., Smart, A., \& Bourne, M. (2001). Theory and practice in SME performance measurement systems. International Journal of Operations and Production Management, 21(8), 1096-1115.

Huotari, M.-L., \& Chatman, E. (2001). Using everyday life information seeking to explain organizational behavior. Library \& Information Science Research, 23, 351-366.

Huotari, M.-L., \& Wilson, T. D. (2001). Determining organizational information needs: The critical success factors approach. Information Research, 6(3). Retrieved from http://www.informationr.net/ir/6-3/paper108.html

Huvila, I. (2010). Information sources and perceived success in corporate finance. Journal of the American Society for Information Science \& Technology, 61, 2219-2229.

Huvila, I. (2013a). "Library users come to a library to find books": The structuration of the library as a soft information system. Journal of Documentation, 69, 715-735.

Huvila, I. (2013b). Meta-games in information work. Information Research, 18(3). Retrieved from http://informationr.net/ir/18-3/colis/paperC01.html

Huvila, I., Anderson, T. D., Jansen, E. H., McKenzie, P., \& Worrall, A. (2017). Boundary objects in information science. Journal of the Association for Information Science and Technology, 68(8), 1807-1822.

Huvila, I., Holmberg, K., Ek, S., \& Widén-Wulff, G. (2010). Social capital in Second Life. Online Information Review, 34, 295-316.

Huvila, I., Lloyd, A., Budd, J. M., Palmer, C., \& Toms, E. (2016). Information work in information science research and practice. Proceedings of the Association for Information Science \& Technology Annual Meeting, 53. https://doi.org/10.1002/pra2.2016.14505301004

Jaeger, P. T., \& Burnett, G. (2010). Information worlds: Social context, technology, and information behavior in the age of the Internet. New York, NY: Routledge.

Jarvis, C.B., MacKenzie, S.B., \& Podsakoff, P.M. (2003).A critical review of construct indicators and measurement model misspecification in marketing and consumer research. Journal of Consumer Research, 30(2), 199-218.

Johnson, J. D. (2003). On contexts of information seeking. Information Processing \& Management, 39, 735-760.

Judge, T. A. (2009). Core self-evaluations and work success. Current Directions in Psychological Science, 18(1), 58-62. Retrieved from http://cdp.sagepub.com/content/18/1/58.abstract

Judge, T. A., \& Hurst, C. (2008). How the rich (and happy) get richer (and happier): Relationship of core self-evaluations to trajectories in attaining work success. Journal of Applied Psychology, 93, 849-863. http://dx.doi.org/10.1037/0021-9010.93.4.849

Judge, T.A., Heller, D., \& Mount, M. (2002). Five-factor model of personality and job satisfaction: A meta-analysis. Journal of Applied Psychology, 87, 530-541.

Justo, R., De Castro, J. O., Coduras, A., \& Cruz, C. (2006). Entrepreneurs' perceptions of success: Examining differences across gender and family status. SSRN eLibrary. Retrieved from http://papers.ssrn.com/sol3/papers.cfm?abstract_id=1019259

Kanter, R. M. (1977). Work and family in the United States: A critical review and agenda for research and policy. New York, NY: Russell Sage Foundation.

Karunakaran, A., Reddy, M. C., \& Spence, P. R. (2013). Toward a model of collaborative 
information behavior in organizations. Journal of the American Society for Information Science \& Technology, 64, 2437-2451.

Kim, H., \& Stoner, M. (2008). Burnout and turnover intention among social workers: Effects of role stress, job autonomy and social support. Administration in Social Work, 32(3), 5-25.

Kim, K. I., Park, H., \& Suzuki, N. (1990). Reward allocations in the United States, Japan, and Korea: A comparison of individualistic and collectivistic cultures. Academy Of Management Journal, 33(1), 188-198.

Klarner, P., Sarstedt, M., Hoeck, M., \& Ringle, C. M. (2013). Disentangling the effects of team competences, team adaptability, and client communication on the performance of management consulting teams. Long Range Planning, 46(3), 258-286.

Krampen, G. (2011). Psychologists' research activities and professional information-seeking behaviour: Empirical analyses with reference to the theory of the intellectual and social organization of the sciences. Journal of Information Science, 37, 439-450.

Kuhlthau, C. C. (1993). Seeking meaning: A process approach to library and information services. Norwood, NJ: Ablex.

Liu, J. (2017). Toward a unified model of human information behavior: an equilibrium perspective. Journal of Documentation, 73, 666-688.

Lloyd, A. (2006). Information literacy landscapes: an emerging picture. Journal of Documentation, 62, 570-583.

Lohmöller, J. B. (2013). Latent variable path modeling with partial least squares. Springer Science \& Business Media.

Lowry, P. B., \& Gaskin, J. (2014). Partial least squares (PLS) structural equation modeling (SEM) for building and testing behavioral causal theory: When to choose it and how to use it. IEEE Transactions on Professional Communication, 57(2), 123-146.

MacKenzie, S. B., Podsakoff, P. M., \& Jarvis, C. B. (2005). The problem of measurement model misspecification in behavioral and organizational research and some recommended solutions. Journal of Applied Psychology, 90(4), 710.

Manning, P. (2010). Explaining and developing social capital for knowledge management purposes. Journal of Knowledge Management, 14(1), 83-99.

Martinez-Canas, R., Saez-Martinez, F. J., \& Ruiz-Palomino, P. (2012). Knowledge acquisition's mediation of social capital-firm innovation. Journal of Knowledge Management, 16(1), 61-76.

Martinko, M. J., Gundlach, M. J., \& Douglas, S. C. (2002). Toward an integrative theory of counterproductive workplace behavior: A causal reasoning perspective. International Journal of Selection and Assessment, 10(1\&2), 36-50.

Meho, L. I., \& Tibbo, H. R. (2003). Modeling the information-seeking behavior of social scientists: Ellis's study revisited. Journal of the American Society for Information Science \& Technology, 54, 570-587.

Meum, T., \& Ellingsen, G. (2011). Standardization in nursing practice: Cross-contextual information sharing. Proceedings of the European Conference on Information Systems, 19. Retrieved from https://aisel.aisnet.org/ecis2011/139/

Molyneux, L., Vasudevan, K., \& Gil de Zúñiga, H. (2015). Gaming social capital: Exploring civic value in multiplayer video games. Journal of Computer-Mediated Communication Volume 20(4). https://onlinelibrary.wiley.com/doi/abs/10.1111/jcc4.12123

Mura, M., Lettieri, E., Radaelli, G., \& Spiller, N. (2013). Promoting professionals' innovative behaviour through knowledge sharing: The moderating role of social capital. Journal of Knowledge Management, 17(4).

Ng, T. W. H., Eby, L. T., Sorensen, K. L., \& Feldman, D. C. (2005). Predictors of objective and subjective career success: A meta-analysis. Personnel Psychology, 58(2), 367-408. 
Ng, T. W.H., \& Feldman, D. C. (2014). Subjective career success: A meta-analytic review. Journal of Vocational Behavior, 85(2), 169-179.

O'Connor, B., Copeland, H., \& Kearns, J. L. (2003). Hunting and gathering on the information savanna. Lanham, MD: Scarecrow Press.

O'Brien, H. L., Dickinson, R., \& Askin, N. (2017). A scoping review of individual differences in information seeking behavior and retrieval research between 2000 and 2015. Library \& Information Science Research, 39, 244-254.

Orser, B., \& Dyke, L. (2005). Gender differences in perceived success among business owners and corporate managers. Proceedings of the Annual International Council for Small Business World Conference, 50. Retrieved from https://icsb.org/wpcontent/uploads/2017/07/iscb2005.pdf.

Parker, B., \& Chusmir, L. H. (1992). A comparison of men and women managers' and nonmanagers' perceptions of success. Human Resource Development Quarterly, 3(1), 73 84.

Peluchette, J. V., \& Jeanquart, S. (2000). Professionals' use of different mentor sources at various career stages: implications for career success. Journal of Social Psychology, 140, 549564.

Petter, S., Straub, D., \& Rai, A. (2007). Specifying formative constructs in information systems research. MIS Quarterly, 31(1), 623-656.

Pierce, J. L., \& Gardner, D. G. (2004). Self-esteem within the work and organizational context: A review of the organization-based self-esteem literature. Journal of Management, 30, 591622.

Pirolli, P., \& Card, S. (1999). Information foraging. Psychological Review, 106, 643-675.

Podsakoff, N.P., \& Organ, D.W., 1986. Self-reports in organizational research: problems and prospects. Journal of Management 12, 531-544.

Porac, J. F., Nottenburg, G., \& Eggert, J. (1981). On extending Weiner's attributional model to organizational contexts. Journal of Applied Psychology, 66(1), 124-126.

Reddy, M. C., \& Jansen, B. J. (2008). A model for understanding collaborative information behavior in context: A study of two healthcare teams. Information Processing \& Management, 44, 256-273.

Reijonen, H., \& Komppula, R. (2007). Perception of success and its effect on small firm performance. Journal of Small Business and Enterprise Development, 14, 689-701.

Rhee, H. L. (2012). Modelling historians' information-seeking behaviour with an interdisciplinary and comparative approach. Information Research, (4), 17. Retrieved from http://www.informationr.net/ir/17-4/paper544.html

Robson, A., \& Robinson, L. (2013). Building on models of information behaviour: Linking information seeking and communication. Journal of Documentation, 69, 169-193.

Saracevic, T. (2016). The notion of relevance in information science: Everybody knows what relevance is. But, what is it really?. Santa Barbara, CA: Morgan \& Claypool.

Savolainen, R. (1995). Everyday life information seeking: Approaching information seeking in the context of "way of life.. Library and Information Science Research, 17, 259-94.

Schuler, R. S., \& Rogocsky, N. (1998). Understanding compensation practice variations across firms: The impact of national culture. Journal Of International Business Studies, 29(1), 159-177.

Simard, C., \& Rice, R. E. (2006). Managerial information behaviour: Relationships among total quality management orientation, information use environments, and managerial roles. Total Quality Management \& Business Excellence, 17(1), 79-95.

Spink, A. (2010). Information behavior: An evolutionary instinct. New York, NY: Springer. Sturges, J. (1999). What it means to succeed: Personal conceptions of career success held by 
male and female managers at different ages. British Journal of Management, 10(3), 239252.

Sutin, A. R., Costa, P. T., Miech, R., \& Eaton, W. W. (2009). Personality and career success: Concurrent and longitudinal relations. European Journal of Personality, 23(2), 71-84.

Talja, S., Keso, H., \& Pietiläinen, T. (1999). The production of "context" in information seeking research: A metatheoretical view. Information Processing and Management, 35, 751-763.

Turban, D. B., \& Dougherty, T. W. (1994). Role of protégé personality in receipt of mentoring and career success. Academy of Management Journal, 37(3), 688-702.

Valcour, P. M., \& Hunter, L. W. (2005). Technology, organizations, and work-life integration. In E. E. Kossek (Ed.) Work and life integration: Organizational, cultural, and individual perspectives (pp. 61-84). Mahwah, NJ: Erlbaum.

Veinot, T. (2010). A multilevel model of HIV/AIDS information/help network development. Journal of Documentation, 66, 875-905.

Walker, E., \& Brown, A. (2004). What success factors are important to small business owners? International Small Business Journal, 22(6), 577-594. Retrieved from http://isb.sagepub.com/cgi/content/abstract/22/6/577

Wetzels, M., Odekerken-Schröder, G., \& Van Oppen, C. (2009). Using PLS path modeling for assessing hierarchical construct models: Guidelines and empirical illustration. MIS Quarterly, 177-195.

Widén, G., Steinerová, J., \& Voisey, P. (2014). Conceptual modelling of workplace information practices: A literature review. Information Research, 19(4). Retrieved from http://www.informationr.net/ir/19-4/isic/isic08.html

Widén-Wulff, G. (2001). Informationskulturen som drivkraft i företagsorganisationen: En kvalitativ studie i finländska försäkringsbolag [Information culture as a driving force in business organization: A qualitative study of Finnish insurance companies] (Unpublished doctoral dissertation). Åbo Akademi University, Turku, Finland.

Widén-Wulff, G., \& Ginman, M. (2004). Explaining knowledge sharing in organizations through the dimensions of social capital. Journal of Information Science, 30, 448-458.

Widén-Wulff, G., Ek, S., Ginman, M., Perttilä, R., Södergård, P., \& Tötterman, A.-K. (2008). Information behaviour meets social capital: A conceptual model. Journal of Information Science, 34, 346-355.

Wilkinson, S. C., Reader, W., \& Payne, S. J. (2012). Adaptive browsing: Sensitivity to time pressure and task difficulty. International Journal of Human-Computer Studies, 70(1), 14 -25 .

Wilson, T. D. (1997). Information behavior: An interdisciplinary perspective. Information Processing and Management, 33, 551-572.

Wilson, T. D. (2009). Information behavior models. In M.J. Bates \& M.N. Maack (Eds.), Encyclopedia of library and information sciences (3rd ed., pp. 2392-2400). New York, NY: Taylor and Francis.

Wong, K. K. K. (2013). Partial least squares structural equation modeling (PLS-SEM) techniques using SmartPLS. Marketing Bulletin, 24(1), 1-32. 